\title{
Lightning Protection of High-speed Railway Traction Power Supply Contact Network
}

\author{
Wulin He \\ Liaoning Railway Vocational and Technical College, Jinzhou, 121013, China \\ 416198816@qq.com
}

Keywords: high-speed railway; traction power supply system contact network; lightning protection

\begin{abstract}
With the continuous development of social economy, high-speed railway has also spread throughout all regions of our country. Because of the high-speed railway higher requirements for safety, the stable operation of the traction power supply system is crucial. In order to well deal with high-speed railway traction power supply catenary of safe problems, and the actual situation of the contact net subjected to lightning strike is studied, so as to find a scientific and reasonable solution and further strengthen the safety system performance of the contact net. This paper mainly starts from the actual situation of lightning protection design of high speed railway, whose design is by the method of lightning strike and the content of calculation, opinions on lightning protection of contact network are put forward, so that the railway can operate safely and stably, guarantee the safety of people's life and property, and promote the smooth operation of China's high-speed railway.
\end{abstract}

\section{Introduction}

In the case of thunderstorm weather, the system will play its role in lightning protection, ensuring the continuous power supply of trains and guaranteeing the safety of people's life and property. Therefore, lightning protection of high-speed railway traction power supply network plays an important role in protecting people's life and property safety. Transportation and economic development are closely related. With the rapid development of social economy, the corresponding transportation industry has also started to develop.Now,China is committed to the development of the transportation industry, especially the rapid development of high-speed railway. However, there are serious deficiencies in the lightning protection of high-speed railway traction power supply in railway construction. Because of high speed railway traction power supply catenary after lightning attack damage is serious, which poses a threat to operation of the high-speed railway, not only can increase tthe death rate of railway passengers, also hinder the smooth operation of high-speed railway in China, leading to a serious threat for economic development of China.

\section{High-speed Railway Traction Power Supply System Construction}

The actual situation of lightning protection construction of high-speed railway:

In view of the problem to the safe operation of high-speed railway, our country has put forward some requirements and regulations, such as: specifications for design of railway traction power supply; the railway lightning protection; electromagnetic compatibility and the interim provisions on the ground engineering, all of the traction power supply system of high-speed railway catenary lightning protection are illustrated, which regulates: average annual thunder day reached more than a month, so this region is a major mine; The annual average lightning day ranges from 40 to 60 days in a high-minefield; The average annual lightning day between 20 and 40 days is a minefield; The average annual lightning day below 20 days is minefield. Because the area is different, the number of lightning days is different, and the situation of lightning strike is different, so it is necessary to design targeted protection measures.

The research and calculation of lightning mode of high-speed railway: 
In general, the number of lightning attacks will increase in areas where lightning strikes frequently and the relationship between the two is growing. Catenary carrier cable generally the average height is seven meters off the ground, and the side clearance is commonly 3 meters, the computation formula is as follows: $\mathrm{N}=0.122 *$ the average number of lightning days per year $* 1.3$. The calculation formula of lightning strike number of compound wire contact net is as follows: $\mathrm{N}=$ $0.244 *$ the average number of lightning days per year *1.3.Because of the lightning strike, the lightning voltage, current condition, the height of the wire and the grounding resistance will affect the damage degree. Therefore, it is necessary to construct the lightning protection by combining these factors, so as to further strengthen the intensity of lightning protection of the contact network.

\section{The Deficiency of Lightning Protection in the Traction Power Supply System of High-speed Railway}

Protection of direct lightning strikes:

High-speed railway traction power supply system of $35 \mathrm{kV}$ voltage level is equal to the power system, Therefore, when constructing lightning protection contact net, the related requirements of $35 \mathrm{k} \mathrm{V}$ transmission line and universal speed railway contact network should be referred. There is no lightning conductor built in all the lightning protection lines of the contact network. In high speed railway, the most common is the viaduct, the viaduct catenary is equal to the height on the ground for the $110 \mathrm{k} \mathrm{V}$ overhead line. However, there is no protection from lightning conductor, so direct lightning will greatly increase the damage to the contact net. Direct lightning strikes generally from the following three aspects: first, the supporting cable is struck by lightning. After being struck by lightning, the insulator of the wrist will appear flashover. Second, the positive feed line is hit by lightning, after the attack the suspension insulator appears flashover; Third, the protection line is hit by lightning, two kinds of insulators will appear flashover Impact grounding resistance problem.

Impact ground resistance problem;

There are many differences between the high-speed railway and the general railway, such as the strong traction current of high-speed railway and the large leakage resistance of the rail. For example, the passenger dedicated line, compared with the rail potential, the current normal speed line requirements are not high. So in the high-speed rail maintenance personnel in the process of work also is vulnerable to lightning, the protection and insulation are weak, causing serious influence for operation of railway traction power supply system. Nowadays, high speed railways use the integrated ground mode, and the earth poles are constructed in some areas, so the requirements for ground resistance docking are relatively high. But in the process of HSR, if struck by lightning, because the intensity of lightning current, in some places there will be a discharge, making the grounding resistance beyond conventional values, which will appear the condition of the insulator.

Different lightning protection requirements in different areas:

Because of different regions, lightning and soil conditions are also different, high speed railway in the build, cross-regional, line is more long, in high speed railway line, the thunder and lightning and the soil are rich. Because of thunder and lightning, the degree of suffering from lightning damage is different, and the lightning protection will have certain relevance. In the process of actual high-speed rail of the lightning protection, for which no gay don't in-depth consideration, it also does not make the lightning protection way comprehensive, so as not to present the utility of lightning protection.

\section{High-speed Railway Traction Power Supply System Contact Network Lightning Protection Solution}

In order to ensure the continuous and orderly operation of the high-speed railway, the corresponding lightning protection should be carried out for the contact network of the traction power supply system. But now, serious deficiencies still exist in the technical level, we must make 
use of the current technical force to constantly improve the protection criterion and protective methods, and reduce the damage by a lightning strike.

Basic guidelines for the use of catenary lightning protection schemes:

First of all, because of high speed railway transportation task is different, some for carrying passengers, high-speed passenger lines, or some railway lines can not only carry passengers, but also carry goods. Because of the different high-speed rail lines, the power supply model is different. Therefore, according to different power supply mode, it appropriates lightning protection. Moreover, because of high speed railway line through an area of broad, high-speed rail needs to face different regions and different environment. The same lightning protection measures are not necessarily suitable for all railway through the area, therefore in the process of lightning protection design, in need of different regions and yard with specific design, building appropriate lightning protection scheme. Third, the use of the lightning protection scheme of the traction power supply system of catenary, not only is considered the different parts of the situation, but also the local average annual lightning attack time for design. According to the statistics of the tripping data, the two can be combined to build the most appropriate lightning protection plan. Fourth, traction power supply system of catenary of lightning protection but also in accordance with the actual situation to adjust the yard contact line and station, to the full range of lightning protection, reduce the problems in the design of lightning protection and lightning accident, hinder the normal operation of the high-speed railway. Fifth, in traction power supply system of catenary of the lightning protection scheme, the actual performance of the lightning rod and wire is also different, because different shanqi, the advantages and disadvantages of the corresponding are also different in order to strengthen the catenary of lightning protection and to meet the differences between shanqi, complement each other. Finally, because of the high speed railway passes through different regions, the corresponding environmental change is more obvious, such as temperature, in different areas of the geographic location, and the contact line lightning protection construction also is considered as the objective factors. When protecting the safety of contact network, reducing the investment of lightning protection equipment and the fund, protecting the integration of lightning protection safety and economic benefits.

The solution of lightning protection for the power supply system of high-speed railway traction power system:

First of all, the high speed railway passes through the area. Because the average lightning for a long time, it's easy to have a thunder weather, some areas or broad plains. Lightning protection is weak in strength, the viaduct is attacked by lightning, which generates serious damage, hinder the normal operation of the high-speed railway. So, these are key areas of lightning protection.

Second, because the contact area is different, the strength of the lightning strike will follow, and lightning protection needs and tripping, statistical data fusion used in, such as wire, the lightning protection method, need to be done according to the degree of lightning arrester of reasonable construction, as well as preventing lightning strike.

Third, in a region, the lightning protection of a catenary in construction of ground wire at the top of the mode, in view of the regional annual average lightning day number, you can set up the lightning rod, lightning protection.

Fourth, lightning protection scope of lightning rod,wire and other equipment is limited, if the comprehensive use, will strengthen its range of lightning protection, and carries on the computation. The lightning protection of potential safety hazard for effective handling reduces some areas because of the lack of protection and lightning strike.

Fifth, at the top of the catenary supporting construction of lightning protection, it can protect pillars on both ends of the high-voltage electric parts for effective lightning protection. At the same time, it also can reduce the direct ray of catenary caused by the high voltage part lightning damage.

Sixth, the catenary wire, rods, if use insulation building mode, and make it independent grounding, which can effectively reduce the catenary pillar of lightning strike and the number of counter ray, reducing the threat posed by lightning strikes on catenary high pressure parts. By using 
this way, it can cut the number of tripping due to lightning, maintaining the safety of the high-speed railway.

Seventh, if catenary is built at the top of the lightning rod, wire, and the distance between the signal equipment is not more than 15 meters, and it will be in the range of catenary wire at the top to increase insulation device. And the top of the each other pillars of independent construction of lightning rod and earthing can reduce lightning protection of signal interference caused by the condition.

Finally, yard contact line lightning protection scheme and the surrounding buildings lightning protection scheme for effective integration, will strengthen the protection of the lightning, which can build the lightning rod in the yard of the more important place, in order to well play the potential of the lightning protection.

\section{Conclusion}

In the process of lightning protection of high-speed railway, there are still many problems in our country,and there is a certain gap between the developed countries and the foreign countries. So, in order to protect the orderly operation of high speed railway power supply system, maintaining the personal property safety of people, relevant staff are needed to constantly enrich their own knowledge of lightning protection, especially for lightning protection measures for high speed railway traction power supply catenary by heart. With the continuous development of social economy, high-speed railway has brought great convenience to people's life, and people's travel has become faster and more comfortable. Of course people focus on railway safety problems, so we need to continue the introduction of foreign advanced technology and experience, using positive and effective lightning protection scheme,in order to reduce the railway power supply system stopped working because of the thunder and lightning attackThe lightning protection of high-speed railway traction power supply in our country will keep up with the times. The rapid development of high-speed railway is the foundation of safe operation. Now the high speed railway traction power supply system of contact line lightning protection in terms of technology, also needs to use more efficient ways of strengthening the ability of the lightning protection, making the operation of the high speed railway secure. In the future, our country also can develop a more complete lightning protection technology, effectively protect the operation of the high-speed railway, protect the vital interests of the passengers, to promote the smooth development of high-speed railway transportation, promote our country's economy growing.

\section{References}

[1] Q.Q.Qian, S.B.Gao, Z.Y.He, Q Z.Chen, J.X.Wu," Key technology of traction power supply for China's high-speed railway,"Chinese Engineering Science, vol.04, pp.9-20, 2015.

[2] S.P.Liu,Z.Q.Han,S.B.Gao,"The protection scheme of power supply arm of high-speed railway based on current characteristics,"Journal of Chinese Electrical Engineering,vol.25,pp. 4437-4442,2014.

[3] B.Kai,W.J.Chen,L.T.Wang,H.B.Shen,R.C.Li,Y.L.Wang,H.J.Zhao,"High-speed railway traction power supply contact network lightning protection,"Journal of Chinese electrical engineering, vol.10,pp.191-199,2013.

[4] L.J.Zhou, F.Gao, R.F.Li, X.B.Cao, G.N.Wu, "Lightning protection system of high speed railway traction power supply system," High voltage technology, vol.02, pp.399-406, 2013.

[5] Contact Lines for Electric Railways. Kiebling, Puschmann, Schmider. 2001

[6] Research on lighting protection performance evaluation of high-speed railway Traction Network.Van Biwu,Gu Shanqiang,Xiang Nianwen,Li Tao,Su Jie,Lu Zejun.2014 International Conference on Lightning Protection (ICLP).

[7] The Modeling of Metal-Oxide Surge Arrester Applied to Improve Surge Protection. M.Karbalaye Zadeh, H.Abniki, A.A.Shayegani Akmal. 2009 2nd International Conference on Power Electronics and Intelligent Transportation System. 